\title{
Efecto de dosis subletales de un herbicida comercial en el sistema nervioso de alevinos de cachama blanca (Piaractus brachypomus)
}

\author{
Effect of dose subletales of a commercial herbicide in the nervous \\ system of alevinos of cachama white (Piaractus brachypomus)
}

Efeito de dose subletales de um herbicida comercial no sistema nervoso de alevinos de cachama branca (Piaractus brachypomus)

\author{
Edwin Gómez-Ramírez ${ }^{1 * *}$, Leslie Guzmán-Beltrán ${ }^{2 *}$, Pedro R. Eslava-Mocha ${ }^{3 *}$; \\ Hernan Hurtado-Giraldo ${ }^{* *}$
}

$1 \mathrm{BSc}, \mathrm{Esp}, \mathrm{cMSc} ;{ }^{2} \mathrm{MV}, \mathrm{Esp} ;{ }^{3} \mathrm{MV}, \mathrm{MSc} ;{ }^{4} \mathrm{BSc}, \mathrm{PhD}$,

* Grupo de investigación sobre sanidad de organismos acuáticos Instituto de Acuicultura, Facultad de Ciencias Agropecuarias y Recursos Naturales, Universidad de los Llanos, Villavicencio, Colombia.

** Grupo de Investigación en Ictiología, Facultad de Ciencias Básicas, Universidad Militar Nueva Granada, Cajicá, Colombia Email: edwin.gomez@unimilitar.edu.co

Recibido: septiembre 4 de $2012 \quad$ Aceptado: noviembre 29 de 2012

\begin{abstract}
Resumen
En Colombia es comúnmente usado el glifosato en labores agrícolas y en la erradicación de cultivos ilícitos de coca y amapola. Este herbicida es aplicado principalmente como Roundup ${ }^{\circledR}$ en varias presentaciones entre ellas Roundup ${ }^{\circledR}$ Active, del herbicida Roundup ${ }^{\circledR}$ se ha demostrado el efecto nocivo en ecosistemas acuáticos afectando varios organismos incluyendo peces, reportándose alteraciones inclusive a bajas concentraciones. El propósito de este trabajo fue determinar cambios histopatológicos en las neuronas sensoriales de los ganglios de la raíz dorsal (GRDs) y en los hemisferios telencefálicos en alevinos de Piaractus brachypomusexpuestos a concentraciones subletales de Roundup ${ }^{\circledR}$ Activo. Se evaluaron tres tratamientos: T1 (0 mg/L de glifosato), T2 (0.1 mg/L de glifosato) y T3 (1 mg/L de glifosato). Los peces fueron expuestos durante 30 días y se mantuvieron en acuarios de 40 Lendensidades de 20 peces/acuario. Se alimentaron tres veces al día (9:00, $12: 00$ y 16:00 h) con alimento comercial al 35\% de proteína bruta ajustada al 5\% de la biomasa total.Se sacrificaron 10 peces y se extrajeron los órganos de interés. Las muestras se fijaron en Karnovsky, postfijadosen tetraóxido de osmio al $2 \%$, se incluyeron en epon. Se realizaron cortes de $1 \mu \mathrm{m}$ y se tiñeron con azul de toluidina.En T1 no se observaron alteraciones histopatológicas. En los hemisferios telencefálicos del T2 y T3 se encontraron células similares a mastocitos en peces, de igual manera estas células aparecieron en las neuronas de GRDs del T3. Otra alteración encontrada en las neuronas de los GRDs fue la presencia de vesículas citoplasmáticas y una leve migración de los núcleos. Los resultados demuestran que la exposición subletal a Roundup ${ }^{\circledR}$ Active induce daños histopatológicos que podrían afectar el desarrollo sensorial de los peces y disminuir de manera indirecta la supervivencia de la especie por la posible incapacidad de reconocer predadores disminuyendola velocidad de respuesta ante una alerta.
\end{abstract}

Palabras clave: Sistema nervioso, Ganglios de la raíz dorsal, Histopatología, Herbicidas, MOAR.

Keywords: nervous system, dorsal root ganglia, Histopathology, Herbicides, MOAR. 